\title{
Climate variability and planktonic communities: The effect of an extreme event (severe drought) in a southern European estuary
}

\author{
Sónia Cotrim Marques*, Ulisses Miranda Azeiteiro, Filipe Martinho, \\ Miguel Ângelo Pardal \\ Department of Zoology, F.C.T., IMAR-Institute of Marine Research, University of Coimbra, 3004-517 Coimbra, Portugal
}

Received 4 December 2006; accepted 13 March 2007

Available online 25 April 2007

\begin{abstract}
As a consequence of climate change, flood and drought events are increasing in frequency throughout the world. Nevertheless, knowledge of the effects on zooplankton estuarine communities is still scarce. The present study aimed to examine zooplankton ecology over two contrasting environmental conditions: regular years and extreme dry years, in a shallow temperate southern European estuary, the Mondego Estuary (Portugal). Monthly samples were carried out during three consecutive years: 2003 characterized as a regular temperate year concerning precipitation and river flow, and an extremely dry period during 2004-2005. The spatial and temporal structure of the biological data was evaluated by a three-mode principal component analysis (PCA), which allowed us to distinguish three distinct ecological areas based on their biological composition and their relationship with hydrologic parameters. The severe drought in 2004-2005 was responsible for spatial shifts in the estuary regarding zooplankton community and interannual variability, with an increase in abundance and diversity during the period of low freshwater flow. This freshwater flow regime influenced the composition of the zooplankton community at the most upstream section of Mondego estuary (zone 3), with a replacement of the freshwater community by one predominantly dominated by estuarine organisms. The occurrence of such estuarine community contributed to the increase in zooplankton abundance which is ascribed to the estuarine species Acartia tonsa. The comparison with previous data obtained for this estuarine ecosystem, demonstrated the occurrence of a different scenario at times of high freshwater flow, being defined the existence of two sub-estuarine systems, the north and south arm, presenting the south one the highest values of abundance.
\end{abstract}

(C) 2007 Elsevier Ltd. All rights reserved.

Keywords: mesozooplankton community; interannual variability; extreme events; three-mode principal component analysis (PCA); estuary

\section{Introduction}

Understanding how climate change will affect the planet is a key issue worldwide (Hays et al., 2005). Estuaries are relatively shallow coastal ecosystems thus sensitive to environmental parameters and frequently under stress because of human population growth and coastal socio-economic development and can be particularly vulnerable to climate changes. Significant environmental factors that affect the structure

\footnotetext{
* Corresponding author.

E-mail address: scotrim@ci.uc.pt (S.C. Marques).
}

(e.g. faunal composition) and function (e.g. secondary production and nutrient cycling) of estuarine systems are expected to be sensitive parameters of global climate change: temperature (e.g. heat waves), freshwater availability, precipitation (e.g. extreme floods and droughts) and runoff (Kennedy et al., 2002). Increases or decreases in precipitation and runoff may create extreme events, floods or droughts respectively, and are increasing in frequency worldwide (Gleick, 2003; Mirza, 2003). The influence of freshwater flowing into estuaries on biological processes and ecosystems development has long been recognized (e.g. Attrill et al., 1999; Kimmerer, 2002). Understanding mechanisms by which estuarine ecosystems 
respond to freshwater flow should thus yield important insights into the dynamics of these key ecosystems as well as their sensitivity to human intervention and climate variability. Changes in marine ecosystems in response to climate change have been widely documented, and a range of studies have highlighted how plankton (and particularly zooplankton) might be important indicators of change in marine systems (e.g. Mackas et al., 1998; Beaugrand et al., 2002; Bonnet and Frid, 2004; Beaugrand, 2005). Zooplankton links primary production to fish production, and responds rapidly to ecosystem alterations (Kiorboe and Nielsen, 1994; Hays et al., 2005) which is achieved by the tight coupling between environmental change and plankton dynamics (Roemmich and McGowan, 1995). Research on the sensitiveness of zooplankton to extreme climate events (e.g. extreme drought) is therefore important as climate influence may disrupt ecological interactions between trophic levels (Molinero et al., 2005). The purpose of this work was to assess the impact of an extreme drought inducing low flow on the zooplankton community by comparing data from the Mondego estuary for "normal/regular years". In recent years several differences in the climate of Portugal have been recorded when compared to the general climate patterns for the period of 1931-1990. There has been a high variability in precipitation [INAG- Portuguese Water Institute (2006), http:// snirh.inag.pt/ and IM-Portuguese Weather Institute (2006), http://web.meteo.pt/pt/clima/clima.jsp]. The hydrological year of 2004/2005 was considered atypical (severe drought), since precipitation in the Mondego river basin area was $45-60 \%$ below average, creating the biggest drought of the twentieth century (http://web.meteo.pt/pt/clima/clima.jsp). Thus a natural experiment has occurred over the time series, providing a unique opportunity to investigate zooplankton ecology over two contrasting environmental conditions, a normal/regular year and an extreme dry year, in a southern European estuary. In addition, we test the applicability of a three-mode principal component analysis (three-mode PCA) that was developed to enable the decomposition of the variance of species in a 3 -dimensional matrix, denoting the variation of species in time and space, at a local scale. In the pelagic realm, methods that allow the simultaneous analyses of complex tables are rare. Recently, such method has been applied by Beaugrand et al. (2000) to Continuous Plankton Recorder (CPR) data, in order to investigate long-term changes in the community structure of a pelagic ecosystem. This study also aimed to offer a framework for zooplankton monitoring programmes in southern Europe.

\section{Materials and methods}

\subsection{Study site}

The Mondego estuary is located on the Atlantic coast of Portugal $\left(40^{\circ} 08^{\prime} \mathrm{N}, 8^{\circ} 50^{\prime} \mathrm{W}\right)$ and comprises two different arms, north and south (Fig. 1), with different hydrological characteristics. The north arm is deeper (4 to $8 \mathrm{~m}$ during high tide, tidal range about 1 to $3 \mathrm{~m}$ ) and constitutes the principal navigation channel. The south arm is shallower ( 2 to $4 \mathrm{~m}$

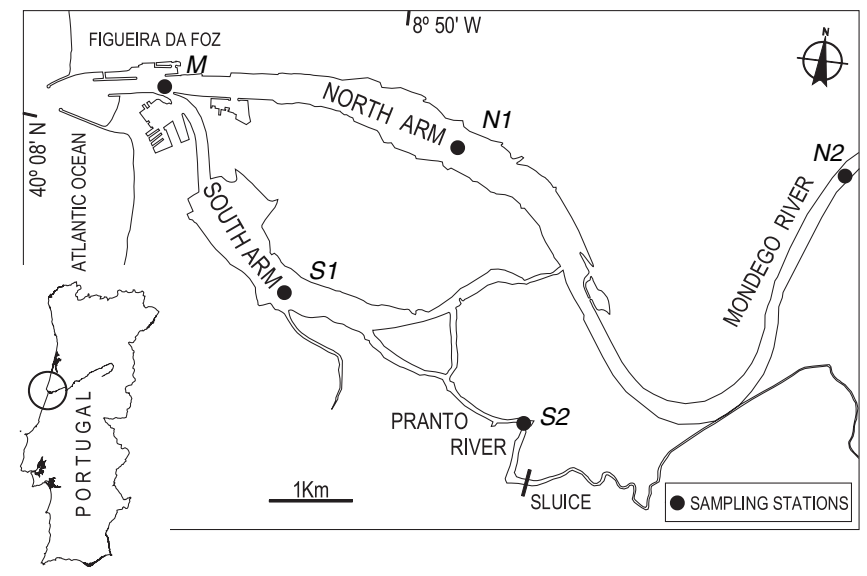

Fig. 1. Map of Mondego estuary showing the sampling stations: M (mouth station), S1 and S2 (southern arm stations) and N1 and N2 (northern arm stations).

during high tide, tidal range 1 to $3 \mathrm{~m}$ ) and is almost silted up in the upper zones, forcing most of the freshwater discharge of Mondego to flow out through the northern arm (Pardal et al., 2000; Cardoso et al., 2004). The south arm constitutes a kind of coastal lagoon in which the water circulation is mostly dependent on the tides and on the freshwater input from the Pranto River (Pardal et al., 2000; Cardoso et al., 2004). Environmental factors in the Mondego estuary provide a large variety of aquatic habitats for populations of marine, brackish and freshwater plankton species (Azeiteiro et al., 1999; Marques et al., 2006), mainly due to salinity and water temperature gradients. Previous studies have shown that the upper reaches of northern arm were dominated by freshwater crustacean mesozooplankton like Acanthocyclops robustus and Diaptomus spp. and the cladocerans Daphnia longispina, Ceriodaphnia pulchella and Bosmina longirostris, often being co-dominant (Marques et al., 2006). The southern arm was occupied by the resident estuarine copepod Acartia tonsa, which was dominant, being the most abundant taxon. The outer part of estuary was characterized by a neritic community with species such as the calanoid copepods Acartia clausi and Temora longicornis and siphonophores Muggiaea atlantica (Azeiteiro et al., 1999; Marques et al., 2006).

\subsection{Biological and hydrological data}

Zooplankton was collected monthly in the Mondego estuary from January 2003 to December 2005 (except in June, August and October 2004) at five stations distributed throughout both arms (Fig. 1). The locations of the sampling stations were defined in order to allow a good spatial coverage of the estuarine ecosystem, ranging from freshwater to marine environment.

Mesozooplankton (adult forms) were collected by subsurface tows using with a $335 \mu \mathrm{m}$ bongo net (mouth diameter: $0.5 \mathrm{~m}$ ), equipped with a Hydro-Bios flowmeter. The water volume filtered was on average $50 \mathrm{~m}^{3}$. The mesh size used was selected to avoid clogging during the tows, especially at 
periods of high production and/or re-suspension of particulate matter. After collection, samples were fixed in $4 \%$ buffered formalin in seawater. Zooplankton samples were counted (number of individuals $\mathrm{m}^{-3}$ ) and identified to the lowest possible taxon. Water samples for the determination of chlorophyll $a\left(\mathrm{Chl}-a, \mathrm{mg} \mathrm{m}^{-3}\right)$ and total suspended solids (TSS, $\mathrm{mg} \mathrm{L}^{-1}$ ) were obtained in each sampling occasion. Measurements of Secchi disk depth (SDD, m) were also made to estimate water transparency. Environmental factors such as temperature $\left({ }^{\circ} \mathrm{C}\right)$ and salinity were also measured at each sampling stations. Additional information about hydrological measurements and zooplankton collection can be found in Marques et al. (2006). Monthly precipitation values were measured at the Soure $13 \mathrm{~F} / 01 \mathrm{G}$ station and acquired from INAG-Instituto da Água (www.snirh.inag.pt). Long-term monthly average precipitation was calculated from data collected at the Soure 13F/01G station from 1933 through 2000. Freshwater discharge from Mondego River was also obtained from one INAG station near the mouth of River, for the study period.

\subsection{Data analyses}

The Mondego zooplankton data base, containing a total of 98 taxa, was used to select the most common species (Table 1) having a minimal frequency of occurrence of 0.35 for each sampling station, as already used elsewhere (e.g. Beaugrand et al., 2000). This cut-off was used to eliminate those taxa having an occurrence falling below that arbitrary-fixed threshold $(0.35)$ in order to decrease the number of zeros in the analyses.

Table 1

List of selected species and codes used in PCA ordination plot

\begin{tabular}{|c|c|c|c|}
\hline Taxon & & Code & Cluster \\
\hline \multirow{10}{*}{ Copepoda } & Acartia clausi & Accl & 1 \\
\hline & Acartia tonsa & Acto & 3 \\
\hline & Calanipeda aquaedulcis & Caaq & 3 \\
\hline & Diaptomus spp. & Diap & 2 \\
\hline & Clausocalanus arcuicornis & Clac & 1 \\
\hline & Paracalanus parvus & Papa & 1 \\
\hline & Temora longicornis & Telo & 2 \\
\hline & Acanthocyclops robustus & Acro & 1 \\
\hline & Corycaeus clausi & Cocl & 1 \\
\hline & Oithona plumifera & Oipl & 1 \\
\hline Chordata & Oikopleura dioica & Oidi & 1 \\
\hline Chaetognatha & Sagitta friderici & Safr & 1 \\
\hline Cirripedia & Nauplius & Naci & 1 \\
\hline \multirow[t]{2}{*}{ Cladocera } & Podon spp. & Podon & 1 \\
\hline & Daphnia-Ceridapnia spp. & Clad & 2 \\
\hline Decapoda & Zoea Carcinus maenas & Zcar & 1 \\
\hline Polychaeta & larvae n.id. & lapo & 1 \\
\hline \multirow[t]{3}{*}{ Cnidaria } & Muggiaea atlantica & Muat & 1 \\
\hline & Lizzia blondina & Libl & 1 \\
\hline & Obelia sp. & Obel & 1 \\
\hline
\end{tabular}

In order to investigate the spatial and temporal variability in the community structure, zooplankton densities were logtransformed, arranged in a three-way table (20 species $\times$ 33 months $\times 5$ stations) and analysed by a three-mode PCA. This method although rarely used in the field of estuarine plankton ecology, has proved to be useful in zooplankton research (Beaugrand et al., 2000). This analysis performs a classical PCA in each mode. In this paper, the first mode denotes the species space, the second mode the time, and the third mode the spatial space. Three classical PCA were performed on the three 2-way tables with 20 species (columns) and 33 months $\times 5$ locations (rows), 33 months (column) and 20 species $\times 5$ locations (rows), 5 locations (columns) and 20 species $\times 33$ months (rows) (see details in Beaugrand et al., 2000). These PCA analyses were performed with CANOCO 4.5 statistical package (ter Braak and Smilauer, 1998). The species scores of the first principal component of the three different modes were then represented graphically in 2 dimensions, i.e., stations $\times$ months (species mode), species $\times$ station (time mode) and species $\times$ month (location mode) to study the community patterns and their evolution during the study period. A cluster analysis using PRIMER statistical package (version 6.0) (Clarke and Warwick, 2001) was computed, composed by the Euclidean distance, in order to group the different variables. Taxa codes used in these analyses are listed in Table 1.

Non-parametric Spearman rank correlations based on the principal component analysis (PCA) were performed to identify those environmental factors that may have played the most significant role in the variability observed in zooplankton abundance.

Salinity anomalies were calculated from the monthly value of salinity by subtracting the corresponding mean for the given time period, and species richness was defined as the mean number of species per sampling station.

\section{Results}

\subsection{Climate-Precipitation}

In the Mondego estuary a clear seasonal pattern of rainfall and freshwater discharge was observed during the 3-year period, with the highest values observed in winter (Fig. 2). In addition, a temporal variability in precipitation was also found. Compared to the mean precipitation regime for central Portugal during 1933-2000 (winter: $355 \mathrm{~mm}$; spring: $224 \mathrm{~mm}$; summer: $47 \mathrm{~mm}$; autumn: $236 \mathrm{~mm}$; sum of monthly values for each season respectively, http://snirh.inag.pt) the year of 2003 corresponded closely to an average precipitation year (winter: $337 \mathrm{~mm}$; spring: $179 \mathrm{~mm}$; summer: $57 \mathrm{~mm}$; autumn: $374 \mathrm{~mm}$ ). Some below-mean precipitation was evident in 2004 (winter: $177 \mathrm{~mm}$; spring: $123 \mathrm{~mm}$ ) and in 2005 (winter: $116 \mathrm{~mm}$; spring: $161 \mathrm{~mm}$; summer: 14; autumn: 197) that corresponded to unprecedented low values, causing one of the biggest drought of the twentieth century in Portugal (Fig. 2). According to the Portuguese Weather Institute (http:// web.meteo.pt/pt/clima/clima.jsp), in these last years drastic 


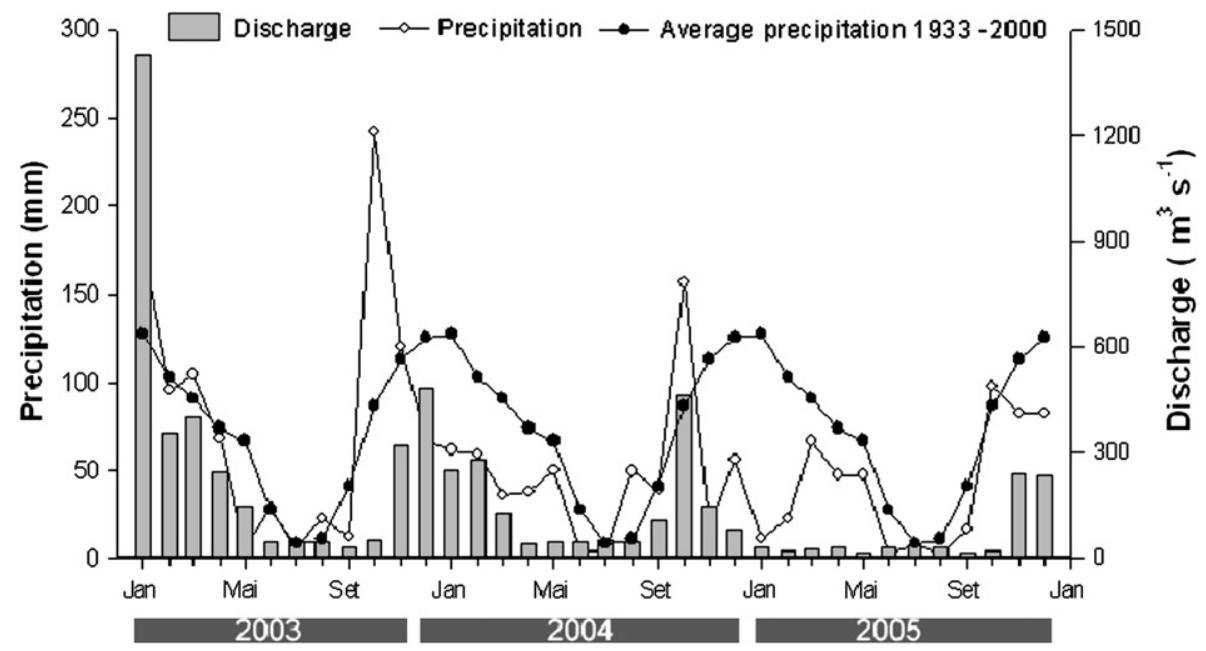

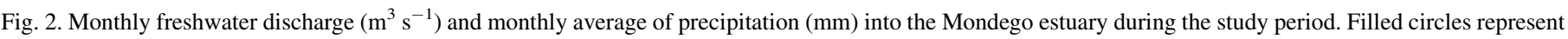
monthly average for the period 1933-2000.

differences in climate have been recorded when compared to the general climate patterns for the period 1961-1990 (Cardoso et al., 2005). These variations of freshwater discharge into the Mondego estuary were clearly influenced by precipitation (Fig. 2), showing a highly significant positive relationship for these two parameters (Spearman rank, $P<0.001$, $r=0.54)$. Strong negative salinity anomalies were detected during 2003 (average precipitation year), especially during the winter (Fig. 3). A completely different scenario was observed in 2005 (extreme drought), where high positive anomalies were observed for the entire estuary and were more pronounced at north arm (stations $\mathrm{N} 1$ and N2). The salinity anomalies values exhibited a highly negative significant $(P<0.001)$ correlation with freshwater discharge.

Concerning air temperatures, the three years presented the typical annual pattern for temperate latitudes, with higher temperatures in spring/summer and lower in fall/winter (data not shown). The values, according to the Portuguese Weather Institute (http://web.meteo.pt/pt/clima/clima.jsp), were similar and close to an average year, calculated as the mean of the last 30 years.

\subsection{Interannual variability}

\subsubsection{PCA: eigenvectors}

From the species ordination plot $(68.25 \%$ of the total variability) shown in Fig. 4a, and the cluster analysis (data not shown), 20 species or taxa could be delineated into three clusters: Cluster 1, composed of 15 taxa, which occurred more frequently in marine environments; cluster 2, representing species from freshwater environments and; cluster 3 composed of typical estuarine organisms. The first axis of the PCA ordination plot separates cluster 2 and 3 from species such as Temora longicornis and Acartia clausi. Cluster s1 and 3 are opposed to cluster 2 on axis 2. Fig. 4b shows the location ordination plot $(78.97 \%$ of variability) and the three zones found by the classification analysis. Each zone is characterized by its particular hydrological conditions and biological variables. Zone 1, mouth and middle south arm, is characterized by salty waters, and as a consequence this zone was mainly composed of marine species of cluster 1. Given that tide propagation is greatest in the north arm, it causes a more pronounced daily salinity change on that particular subsystem of Mondego estuary. Additionally, the freshwater discharge into the estuary occurs mainly in the north arm, contributing to the high fluctuation on the hydrological conditions. These conditions were reflected in the distribution and composition of zooplankton at zone 2. Therefore, this zone acts as a transitional one between zones 1 and 3. Although being dominated by species from cluster 1 , taxa which belong to clusters 2 and 3 were frequently observed, probably being advected from upstream, particularly in winter/spring, when river discharge was higher (see Fig. 2). Zone 3, the upper reaches of the estuary, is characterized by lower salinity values and higher temperatures, being dominated by species related with clusters 2 and 3 . The first and the second axis separate zone 3, from both zone 1 and 2. Axis 2 showed also locations of zone 1 to be opposite to zone 2. Concerning Fig. 4c, seasonal patterns were hardly detectable by the analysis of the time ordination and also by the cluster analysis.

\subsubsection{PCA: principal component}

Fig. 5 shows the results only for the first principal component since it explained the major variability in the species density. For the first principal component time-location (species mode) (Fig. 5a), a strong monthly variation was observed in zones 1 and 2, mouth and middle estuary, respectively. In zone 3, upper estuary, monthly variability in species densities was much lower. Highest abundances occurred during the last year surveyed, 2005, from August to December, especially in zone 3. During year 2003, low densities were observed from January to July in all study area and in 2004 from August to December. In the first principal component species-time (location mode), species of cluster 2 , which were found mainly in 

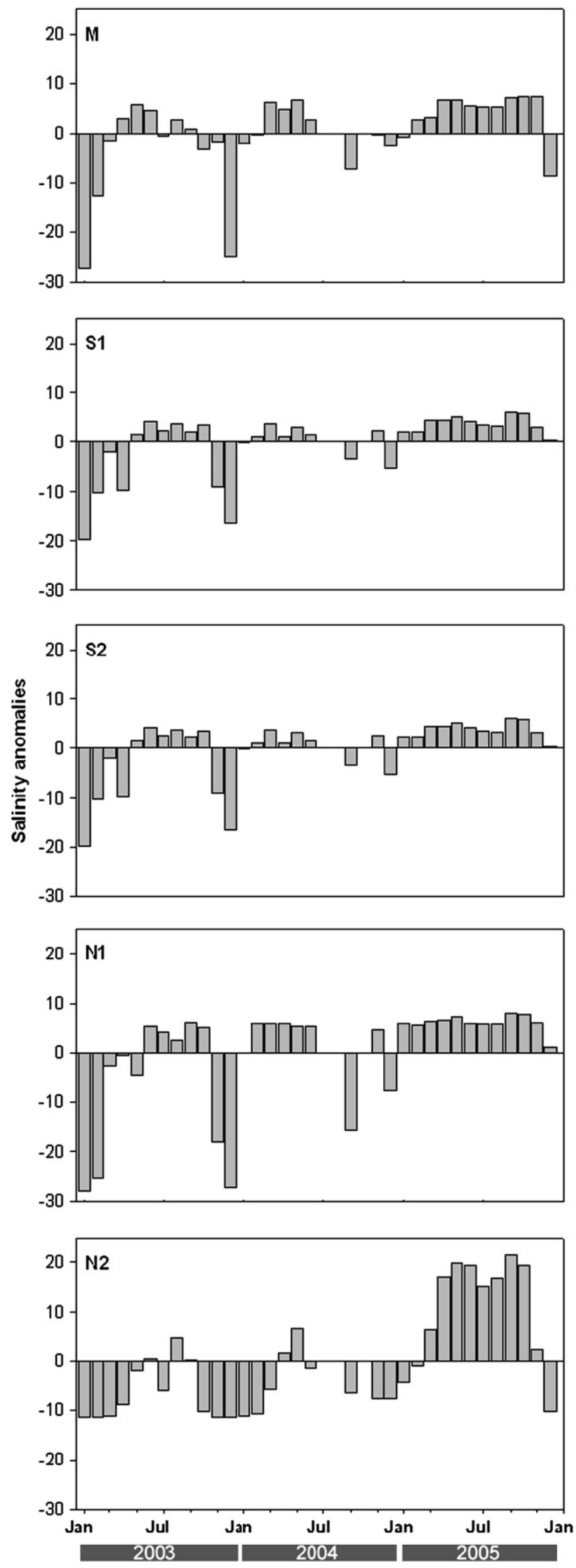

Fig. 3. Inter-annual monthly anomalies of salinity for the five sampling stations. the upper estuary, showed a monthly variation that can be translated in higher densities in winter, particularly in 2003 (Fig. 5b).

The first principal component species-location (time mode) exhibited a gradient along the study area (Fig. 5c). Cluster 1, composed of marine species, dominated mainly at the mouth and middle estuary. Although freshwater and estuarine species (cluster 2 and 3, respectively) were more restricted to the upper estuary, they were also found at middle north arm and with much lower densities at the mouth of estuary.

\subsubsection{Zooplankton and hydrological parameters}

In Table 2, a comprehensive data set covering both the nondrought (2003) and drought (2004 to 2005) period is available for comparative observation of drought-induced changes in estuarine water physico-chemical parameters. Increases in salinity are particularly apparent during the dry years, for the whole estuary, being more pronounced during winter months. Differences in temperature values were considerable in the upstream stations (S2 and N2); with recorded increases in the winter months and decreases in summer months. More typical values were recorded for the middle and lower reaches of estuary. Chlorophyll $a$ showed a rise in the mean of station S2 owing to an increase during early summer and autumn. A pronounced decrease in latter spring at station $\mathrm{N} 2$ resulted in a decrease of Chl- $a$ values. Finally, with the exception of a rise in stations S2, suspended solids showed no marked changes (Table 2).

In order to understand the spatio-temporal changes in species abundance, correlations between the first principal component time-location and the hydrological parameters were calculated for each cluster analysis zone. For the mouth and middle estuary of the south arm, Spearman correlation analysis show significant correlation with temperature $(P<0.05$, $r=0.45)$, Chl- $a \quad(P<0.05, \quad r=0.51), \quad$ TSS $\quad(P<0.05$, $r=0.37)$ and $\operatorname{SDD}(P<0.05, r=0.61)$ with first principal component scores. A positive relationship between PC1 and salinity was found for the upper estuary $(P<0.05, r=0.72)$ and middle north arm $(P<0.05, r=0.40)$. In this last zone, however, the correlation coefficient was not so strong. A positive relationship was also found for Chl- $a$ and SDD for both zones.

\subsubsection{Interannual monthly changes in diversity}

Fig. 6 shows the major spatio- (stations) and temporal (season and interannual) patterns in mesozooplankton species richness in Mondego estuary. Generally, a high diversity was observed in the mouth and middle estuary, zones 1 and 2, respectively, compared to the upper estuary. By analysis of Fig. 6 an increase in species richness values in the upstream areas in 2005 could be observed, particularly during spring and summer.

\section{Discussion}

The comprehensive data set from the Mondego estuary of mesozooplankton populations and environmental parameters 

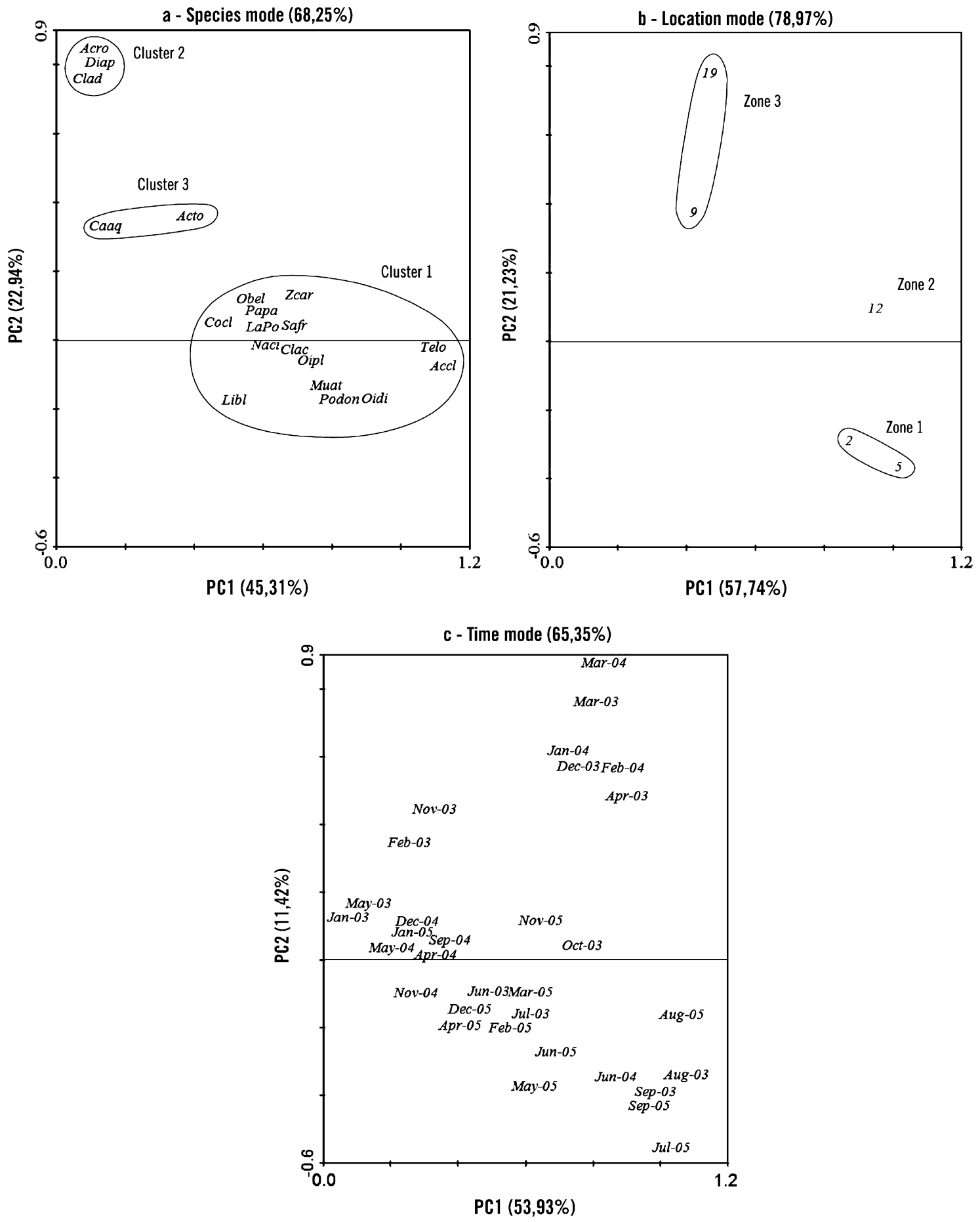

Fig. 4. Results of PCA analysis. (a) Species ordination. Correlations between species and the 2 first principal component location-time. (b) Location ordination. Correlation between the stations and the 2 first principal components species-time. (c) Time ordination. Correlation between month and the 2 first principal components species-location. Percentage of variance explained by the components is given in parentheses.

presented here allows a detailed evaluation of the effects induced by severe drought in the mesozooplankton dynamics. The drought period reported here was the most severe recorded in Portugal during recent decades (http://web.meteo.pt/pt/clima/clima.jsp). This allowed the comparison of population fluctuations with those described for the predrought period (Marques et al., 2006). Furthermore, annual freshwater input into the ecosystem changed significantly during the period of 2003-2005, reflecting the change of the normal climate regime for this region, verified during that period. Although this time series is too short to define long-term trends (Beaugrand et al., 2000; Kimmel and Roman, 2004), it was still possible to detect some consistent changes in biological and hydrological variables over the study period. 
a
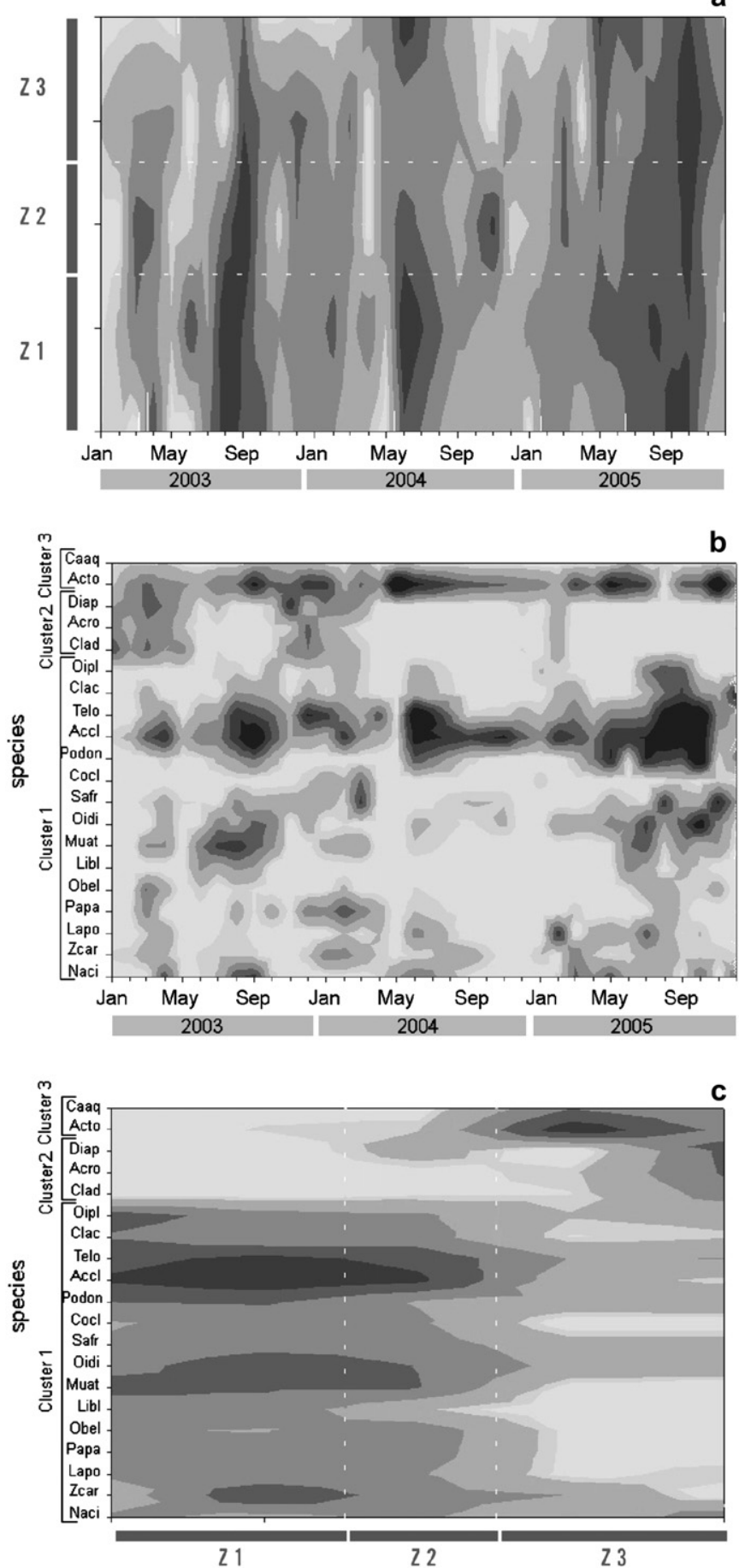

Fig. 5. Variability of the first principal component for (a) location-time (species mode). The grey shading indicates the intensity of the first component. The groups determined from the cluster analysis are indicated for location (b) species-year (location mode) on the ordinate. The groups determined from the cluster analysis are indicated for species on the ordinate and for years on the abscissa. Z1: mouth and downstream station of south arm; Z2: upper reaches of estuary; Z3: intermediate station of north arm. (c) location-species (time mode). The groups determined from the cluster analysis are indicated for species on the abscissa and for locations on the ordinate. Taxa codes are listed in Table 1.

\subsection{Consequences of drought events on the zooplankton community}

The use of multivariate analysis (cluster and PCA) allowed us to distinguish three distinct ecological areas based on their biological composition and their relationship with hydrologic parameters. The first zone comprises the mouth and middle section of south arm of Mondego estuary where water circulation is predominantly dependent on the tides (Pardal et al., 2000; Marques et al., 2003). The most representative species of this zone are those grouped on cluster 1, such as Acartia clausi, Temora longicornis, Oithona dioica and Muggiaea atlantica whose occurrence is favoured by the seawater penetration and frequently distributed at the most downstream regions of European estuarine ecosystems (Mouny and Dauvin, 2002; Leandro et al., 2006). Zooplankton abundance in zone 1 was shown to be significantly positively correlated with temperature, indicating that the abundance of zooplankton organisms depends on its seasonal cycle. The second zone comprises the middle north arm and defines a transition area influenced by tides and by freshwater flow in years of high precipitation. This area is mainly characterized by marine species; however, estuarine and freshwater taxa were also frequently observed, especially during winter/spring of 2003 when river discharge increased. The spatial distribution of the marine assemblages was shown to be related with the high or low level of seawater intrusion. In zone 3, upper estuary, the community was dominated by Acartia tonsa a species characteristic of brackish waters (Escaravage and Soetaert, 1995; Cervetto et al., 1999). At periods of highest flow a freshwater community was also observed, composed mainly of Acanthocyclops robustus, Diaptomus sp. and the freshwater cladocerans Daphnia longispina, Ceriodaphnia sp. and Bosmina longirostris, as observed in other estuaries with significant freshwater flow (Tackx et al., 2004). A different scenario was noted by Marques et al. (2006) for this system at times of high freshwater flow. These authors defined the existence of two sub-estuarine systems: the south arm that is dominated by tidal action and freshwater discharges of a small tributary river (Pranto River) and the north arm which is greatly influenced by freshwater discharges from the Mondego River. Additionally, highest densities were found at the south arm possibly as a direct consequence of the low advection effect on planktonic populations compared to the north arm (Marques et al., 2006). In the present study, during the dry years of 2004 and 2005 a progressive increase in density and species richness was observed, especially in the north arm. In this period, the extremely low freshwater flow from the Mondego River allowed a major penetration of seawater into the north arm and consequently higher zooplankton diversity. This shift in freshwater flow regime during drought years also influenced the composition of the zooplankton community as described above. At the most upstream sections of the Mondego estuary, namely in the north arm, a replacement of the freshwater community by an estuarine community has been observed during the last two years, highlighting the influence of the recent drought period. The occurrence of an 
Table 2

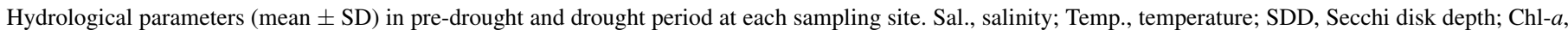
chlorophyll $a$; TSS, total suspended solid

\begin{tabular}{|c|c|c|c|c|c|c|}
\hline & & \multicolumn{5}{|c|}{ Abiotic parameters } \\
\hline & & Sal. & $\begin{array}{l}\text { Temp. } \\
\left({ }^{\circ} \mathrm{C}\right)\end{array}$ & $\begin{array}{l}\text { SDD } \\
(\mathrm{m})\end{array}$ & $\begin{array}{l}\text { Chl- } a \\
\left(\mathrm{mg} \mathrm{m}^{-3}\right)\end{array}$ & $\begin{array}{l}\text { TSS } \\
\left(\mathrm{mg} \mathrm{L}^{-1}\right)\end{array}$ \\
\hline \multirow[t]{5}{*}{ Pre-drought } & M & $24.2(11.1)$ & $15.5(3.0)$ & $1.9(0.8)$ & $3.9(1.8)$ & $23.9(5.0)$ \\
\hline & $\mathrm{S} 1$ & $25.5(8.5)$ & $15.6(2.5)$ & $1.6(0.5)$ & $3.1(1.5)$ & $24.1(5.5)$ \\
\hline & $\mathrm{S} 2$ & $14.2(8.4)$ & $17.3(4.8)$ & $0.5(0.1)$ & $9.2(6.1)$ & $28.3(12.2)$ \\
\hline & N1 & $21.0(13.7)$ & $15.8(3.1)$ & $1.6(0.8)$ & $3.4(1.5)$ & $22.4(9.7)$ \\
\hline & $\mathrm{N} 2$ & $3.4(4.7)$ & $17.1(4.8)$ & $0.9(0.3)$ & $9.6(15.0)$ & $15.3(12.7)$ \\
\hline \multirow[t]{5}{*}{ Drought } & M & $31.4(4.8)$ & $14.8(2.3)$ & $2.5(1.0)$ & $3.2(2.1)$ & $22.2(9.3)$ \\
\hline & $\mathrm{S} 1$ & $32.0(2.8)$ & $15.2(2.2)$ & $1.6(0.4)$ & $3.7(1.9)$ & $25.4(10.5)$ \\
\hline & $\mathrm{S} 2$ & $25.2(5.6)$ & $18.2(6.0)$ & $0.5(0.1)$ & $11.0(8.4)$ & $34.5(16.7)$ \\
\hline & N1 & $31.9(5.7)$ & $15.1(2.3)$ & $1.8(0.7)$ & $3.5(2.1)$ & $24.5(9.7)$ \\
\hline & $\mathrm{N} 2$ & $11.3(9.7)$ & $16.5(4.8)$ & $1.2(0.3)$ & $7.3(4.8)$ & $14.6(8.6)$ \\
\hline
\end{tabular}

estuarine community contributed to the increase in zooplankton abundance which is attributed to the estuarine species A. tonsa. No clear seasonal pattern was defined in this study. A possible explanation for this could be attributed to the abnormal variation in precipitation, especially in winter months as seen during the study period.

\subsection{Hypothesis of reduced river flow}

The reduced river flow, caused by the general evolution of climate conditions (lower precipitation), was the main factor that induced the trend observed for zooplankton densities in Mondego estuary during the period 2003-2006. Advection is regarded as a key mechanism explaining zooplankton distribution and abundance (e.g. Sundby, 2000; Roman et al., 2001; Lindley and Daykin, 2005). It is well known that the diffusive and advective properties of freshwater discharge play a critical role in the population distribution patterns and richness, as well as in its temporal variability (Licandro and Ibanez, 2000). This agrees in part with our findings since a negative significant correlation between the abundance of zooplankton

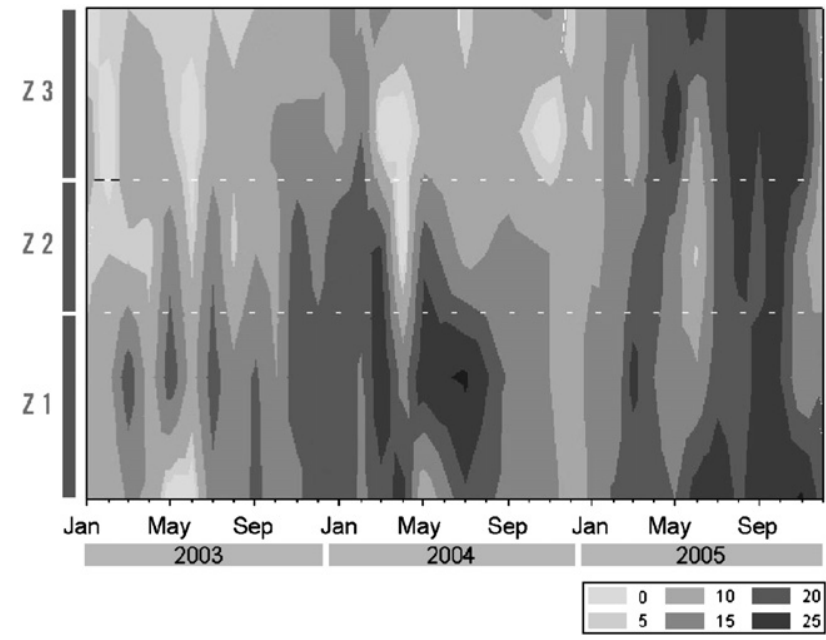

Fig. 6. Inter-annual monthly changes in species richness in the Mondego estuary. and river discharge was observed. Based on such relationship, we can assume that the zooplankton organisms of the Mondego estuary may have been drifted away during higher freshwater flow. During the period reported in this study, river flow was particularly critical for the dominant species Acartia tonsa. This copepod species is a broadcaster spawner, laying its eggs freely on the water column which are consequently more susceptible to advective transport (Kimmel et al., 2006) with implications on the population dynamics in addition to flushing out of other developmental stages (abundance decrease). During dry years, it is possible for A. tonsa to develop from egg to adult without being flushed from the estuary. Likewise, the variability of the advective transport as a consequence of the freshwater flow had significant implications on the zooplankton distribution patterns in this region. With the decreasing trend of river flow are associated variations of hydrological parameters such as salinity and TSS (Castel, 1995). The high salinity values recorded during the dry period are the result of an abnormal low year in terms of rainfall regime and confirmed by the significantly correlation between salinity and precipitation. Salinity has a strong influence on the distribution of zooplankton organisms (Mouny and Dauvin, 2002; David et al., 2005; Uriarte and Villate, 2005), and has been considered to be the main factor responsible for the distribution of zooplankton in coastal zones directly influenced by freshwater inputs (Vincent et al., 2002; Kimmel and Roman, 2004; Molinero et al., 2005).

The apparent positive dependence of zooplankton abundance on the TSS and SDD could be attributed to the significant positive correlation between such hydrological parameters with salinity. At times of low freshwater flow, tidal propagation through estuary brings more organisms to the ecosystem, also promoting sediment re-suspension.

We also found that zooplankton abundance was significantly positively correlated with $\mathrm{Chl}-a$, indicating that the abundance of these organisms was associated with phytoplankton biomass. Some mechanisms have been hypothesised in order to explain the relationship between phytoplankton in terms of Chl- $a$ and zooplankton, including changes in primary production and zooplankton (Durbin and Durbin, 1981; Vargas 
and Gonzalez, 2004). It is believed that abundant food in the form of phytoplankton, results in high zooplankton concentrations (Roman et al., 2001). At the present we do not have estimates of phytoplankton and microzooplankton available as food for zooplankton. From our results, it seems clear that seasonal and inter-annual scale abundance of zooplankton is influenced by food availability given the high Chl- $a$ concentration at the upper estuary (Marques et al., 2006) but that its implication for zooplankton abundance remains unknown.

\section{Conclusions}

Any change in climate will have consequences on the pelagic community and consequently on the functioning of the ecosystems as reported elsewhere (e.g. Castel, 1995; Beaugrand et al., 2002; Chiba et al., 2006; Kamburska and Fonda-Umani, 2006). The present study has clearly detected the influence of extreme drought-induced variations in hydrological conditions on zooplankton dynamics in Mondego estuary. These conclusions are crucial for the ecological role played by climate change events on the structure of zooplankton communities. It seems that these findings could have immediate implications deserving attention for the assessment and modelling studies of pelagic ecosystems and biogeochemical fluxes in estuarine/coastal systems, since mesozooplankton play an important role in linking estuarine primary production with fish production (Munk et al., 2003; Kimmel and Roman, 2004). Nevertheless it is known that 3 years of consecutive data are very preliminary, and more research should be conducted especially to determine further the relationship between climate regime and zooplankton populations. Much longer data series have to be encouraged in this system and elsewhere, as all of this information may help to a better understanding of the zooplankton variability in other temperate ecosystems. On-going plankton monitoring programmes around the world can act as sentinels to identify future changes in marine ecosystems. Crucial to identifying these future changes are the maintenance of plankton time-series and the funding of projects that continue to enhance the unique data sets that these time-series provide. One major difficulty in studying the impact of climate change, like extreme events (e.g. floods and droughts), on any species is to know the degree of adaptability of the life cycle in response to environmental variability (e.g. Hansen et al., 2003). A relatively simple but rarely possible approach to estimate the adaptability of a species is to study a population over a long period encompassing important environmental fluctuations. To detect, understand and anticipate modifications in pelagic ecosystems induced by climate change, a large monitoring system would undoubtedly be needed.

\section{Acknowledgements}

The present work was supported by I.I.I. (Instituto de Investigação Interdisciplinar of the University of Coimbra) through a $\mathrm{PhD}$ grant awarded to S.C.M. (III/AMB/28/2005). A special thanks to all colleagues that helped during field work.

\section{References}

Attrill, M.J., Power, M., Thomas, R.M., 1999. Modelling estuarine Crustacea population fluctuations in response to physico-chemical trends. Marine Ecology Progress Series 178, 89-99.

Azeiteiro, U.M.M., Marques, J.C., Ré, P., 1999. Zooplankton annual cycle in the Mondego river estuary (Portugal). Arquivos Museu Bocage 3, 239-263.

Beaugrand, G., 2005. Monitoring pelagic ecosystems from plankton indicators. ICES Journal of Marine Science 62, 333-338.

Beaugrand, G., Ibanez, F., Reid, P.C., 2000. Spatial, seasonal and long-term fluctuations of plankton in relation to hydroclimatic features in the English Channel, Celtic Sea and Bay of Biscay. Marine Ecology Progress Series 200, 93-102.

Beaugrand, G., Reid, P.C., Ibanez, F., Lindley, J.A., Edwards, M., 2002. Reorganization of North Atlantic marine copepod biodiversity and climate. Science 296, 1692-1694.

Bonnet, D., Frid, C.L.J., 2004. Seven copepod species considered as indicators of water-mass influence and changes: results from a Northumberland coastal station. ICES Journal of Marine Science 61, 485-491.

ter Braak, C.J.F., Smilauer, P., 1998. CANOCO Reference Manual and User's Guide to Canoco for Windows: Software for Canonical Community Ordination (Version 4). Microcomputer Power, Ithaca, NY, USA, 352 pp.

Cardoso, P.G.M., Pardal, M.A., Lilleb $\varnothing$, A.I., Ferreira, S.M., Raffaelli, D., Marques, J.C., 2004. Dynamics change in seagrass assemblages under eutrophication and implication for recovery. Journal of Experimental Marine Biology and Ecology 302, 233-248.

Cardoso, P.G., Brandão, A., Pardal, M.A., Raffaelli, D., Marques, J.C., 2005. Resilience of Hydrobia ulvae populations to anthropogenic and natural disturbances. Marine Ecology Progress Series 289, 191-199.

Castel, J., 1995. Long-term changes in the population of Eurytemora affinis (Copepoda, Calanoida) in the Gironde estuary (1978-1992). Hydrobiologia $31,85-101$.

Cervetto, G., Gaudy, R., Pagano, M., 1999. Influence of salinity on the distribution of Acartia tonsa (Copepoda, Calanoida). Journal of Experimental Marine Biology and Ecology 239, 33-45.

Chiba, S., Tadokoro, K., Sugisaki, H., Saino, T., 2006. Effects of decadal climate change on zooplankton over the last 50 years in the western subarctic North Pacific. Global Change Biology 12, 907-920.

Clarke, K.R., Warwick, R.M., 2001. Change in Marine Communities. An Approach to Statistical Analyses and Interpretation, second ed. Primer-E, Plymouth, UK, $172 \mathrm{pp}$.

David, V., Sautour, B., Chardy, P., Leconte, M., 2005. Long-term changes of the zooplankton variability in a turbid environment: the Gironde estuary (France). Estuarine, Coastal and Shelf Science 64, 171-184.

Durbin, A.G., Durbin, E.G., 1981. Standing stock and estimated production rates of phytoplankton and zooplankton in Narragansett Bay, Rhode Island. Estuaries 4, 24-41.

Escaravage, V., Soetaert, K., 1995. Secondary production of the brackish copepod communities and their contribution to the carbon fluxes in the Westerschelde estuary (The Netherlands). Hydrobiologia 311, 103-114.

Gleick, P., 2003. Global Fresh Water Resources: Soft-path Solutions for the 21st Century. Science Magazine 302, 1524-1528.

Hansen, A.S., Nielsen, T.G., Levinsen, H., Madsen, S.D., Thingstad, T.F., Hansen, B.W., 2003. Impact of changing ice cover on pelagic productivity and food web structure in Disko Bay, West Greenland: a dynamic model approach. Deep-Sea Research Part II 50, 171-187.

Hays, G.C., Richardson, A.J., Robinson, C., 2005. Climate change and marine plankton. Trends in Ecology and Evolution 20, 337-344.

Kamburska, L., Fonda-Umani, S., 2006. Long-term copepod dynamics in the Gulf of Trieste (Northern Adriatic Sea): Recent changes and trends. Climate Research 31, 195-203.

Kennedy, V.S., Twilley, R.R., Kleypas, J.A., Cowan Jr., J.H., Hare, S.R., 2002. Coastal and Marine Ecosystems and Global Climate Change. Pew Center on Global Climate Change, Arlington, VA, 64 pp.

Kimmel, D.G., Roman, M.R., 2004. Long-term trends in mesozooplankton abundance in Chesapeake Bay USA: influence of freshwater input. Marine Ecology Progress Series 267, 71-83. 
Kimmel, D.G., Miller, W.D., Roman, M.R., 2006. Regional scale climatic forcing of Chesapeake Bay zooplankton dynamics. Estuaries and Coasts 29, 375-387.

Kimmerer, W.J., 2002. Effects of freshwater flow on abundance of estuarine organisms: physical effects or trophic linkages. Marine Ecology Progress Series 243, 39-55.

Kiorboe, T., Nielsen, T.G., 1994. Regulation of zooplankton biomass and production in a temperate, coastal ecosystem. 1. Copepods. Limnology and Oceanography 39, 493-507.

Leandro, S.M., Tiselius, P., Queiroga, H., 2006. Growth and development of nauplii and copepodites of the estuarine copepod Acartia tonsa from southern Europe (Ria de Aveiro, Portugal) under saturating food conditions. Marine Biology 150, 121-129.

Licandro, P., Ibanez, F., 2000. Changes of zooplankton communities in the Gulf of Tigullio (Ligurian Sea, Western Mediterranean) from 1985 to 1995. Influence of hydroclimatic factors. Journal of Plankton Research 22, 2225-2253.

Lindley, J.A., Daykin, S., 2005. Variations in the distributions of the Centropages chierchiae and Temora stylifera (Copepoda: Calanoida) in the north-eastern Atlantic Ocean and western European shelf waters. ICES Journal of Marine Science 62, 860-877.

Mackas, D.L., Goldblatt, R., Lewis, A.G., 1998. Interdecadal variation in developmental timing of Neocalanus plumchrus populations at Ocean Station P in the subarctic North Pacific. Canadian Journal of Fisheries and Aquatic Sciences 55, 1878-1893.

Marques, J.C., Nielsen, S.N., Pardal, M.A., Jørgensen, S.E., 2003. Impact of eutrophication and river management within a framework of ecosystem theories. Ecological Modelling 166, 147-168.

Marques, S.C., Azeiteiro, U.M., Marques, J.C., Neto, J.M., Pardal, M.A., 2006. Zooplankton and ichthyoplankton communities in a temperate estuary: spatial and temporal patterns. Journal of Plankton Research 28, 297-312.

Mirza, M.M.Q., 2003. Climate change and extreme weather events: can developing countries adapt? Climate Policy 3, 233-248.

Molinero, J.-C., Ibanez, F., Nival, P., Buecher, I., Souissi, S., 2005. North Atlantic climate and northwestern Mediterranean plankton variability. Limnology and Oceanography 50, 1213-1220.
Mouny, P., Dauvin, J.-C., 2002. Environmental control of mesozooplankton community structure in Seine estuary (English Channel). Oceanologica Acta 25, 13-22.

Munk, P., Hansen, B.W., Nielsen, T.G., Thomsen, H.A., 2003. Changes in plankton and fish larvae communities across hydrographic fronts off West Greenland. Journal of Plankton Research 25, 815-830.

Pardal, M.A., Marques, J.C., Metelo, I., Lilleb $\varnothing$, A.I., Flindt, M.R., 2000. Impact of eutrophication on the life cycle, population dynamics and production of Ampithoe valida (Amphipoda) along an estuarine spatial gradient (Mondego estuary, Portugal). Marine Ecology Progress Series 196, 207-219.

Portuguese Water Institute (Instituto da Água), 2006. http://www.snirh.inag.pt (accessed July 2006)

Portuguese Weather Institute (Instituto de Metereologia), 2006. http://web. meteo.pt/pt/clima/clima.jsp (accessed July 2006).

Roemmich, D., McGowan, J., 1995. Climatic warming and the decline of zooplankton in the California current. Science 267, 1324-1326.

Roman, M.R., Holliday, D.V., Sanford, L.P., 2001. Temporal and spatial pattern of zooplankton in the Chesapeake Bay turbidity maximum. Marine Ecology Progress Series 213, 215-227.

Sundby, S., 2000. Recruitment of Atlantic cod stocks in relation to temperature and advection of copepod populations. Sarsia 85, 277-298.

Tackx, M., Pauw, N., Van Mieghem, R., Azémar, F., Hannouti, A., Damme, S., Fiers, F., Daro, N., Meire, P., 2004. Zooplankton in the Schelde estuary, Belgium and the Netherlands' Spatial and temporal patterns. Journal of Plankton Research 26, 133-141.

Uriarte, I., Villate, F., 2005. Differences in the abundance and distribution of copepods in two estuaries of the Basque coast (Bay of Biscay) in relation to pollution. Journal of Plankton Research 27, 863-874.

Vargas, C.A., Gonzalez, H.E., 2004. Plankton community structure and carbon cycling in a coastal upwelling system. I. Bacteria, microprotozoans and phytoplankton in the diet of copepods and appendicularians. Aquatic Microbial Ecology 34, 151-164.

Vincent, D., Luczak, C., Sautour, B., 2002. Effects of a brief climatic event on zooplankton community structure and distribution in Arcachon Bay (France). Journal of the Marine Biological Association of the United Kingdom 82, 21-30. 